\title{
Control of Cell Adhesion and Detachment on a Nanostructured Scaffold Composed of Light-responsive Gas-generating Film
}

\author{
Yoshinori Akagi, ${ }^{*}$ Shuichiro Matsumoto, ${ }^{1}$ and Shohei Yamamura ${ }^{2}$ \\ ${ }^{1}$ Sekisui Chemical Co., Ltd., 2-1 Hyakuyama, Shimamoto-cho, Mishima-gun, Osaka 618-0021, Japan \\ ${ }^{2}$ Health Research Institute, National Institute of Advanced Industrial Science and Technology (AIST), \\ 2217-14 Hayashi-cho, Takamatsu, Kagawa 761-0395, Japan
}

(Received August 6, 2018; accepted December 12, 2018)

Keywords: cell adhesion, cell detachment, nanostructure, azido polymer, cancer cell

The standard method of detaching adherent cells from a culture substrate involves the application of trypsin to digest the extracellular matrix. However, the trypsin treatment is time-consuming and sometimes causes damage to the cells when harvesting cells from a culture dish. We have developed a novel nanostructured scaffold composed of a lightresponsive gas-generating film (gas-generation nanoscaffold) that serves the dual functions of cell adhesion and cell detachment. Cell adhesion was based on the nanostructured surface topography with numerous holes of $230 \mathrm{~nm}$ diameter and $200 \mathrm{~nm}$ depth; the structure was created by soft lithography. Cell detachment was accomplished by the light irradiation of the photodecomposable polymer film to generate gas, which weakens the adhesive forces between the cells and the substrate. $11 \mu \mathrm{l}$ of $\mathrm{N}_{2}$ gas was generated in $90 \mathrm{~s}$ and the gas-generation rate was $0.1 \mu \mathrm{l} / \mathrm{s}$. It was found that twice as many human bronchioalveolar carcinoma cells (NCL-H1650) adhered to the nanoscaffold than to the same scaffold without the nanostructure. The nanoscaffold exhibited no cytotoxicity according to cell viability and cytotoxicity assays. After culturing the cells on the gas-generation nanoscaffold, they were irradiated with light to generate gas, which causes the cells on the film to detach. We successfully demonstrated cell adhesion and cell detachment on the novel gas-generation nanoscaffold. This novel material is expected to be useful as an alternative cell culture substrate without the need for the standard trypsin treatment.

\section{Introduction}

Tissue engineering has been widely explored within the field of biomedicine since the first groundbreaking study by Langer and Vacanti during the 1980s. ${ }^{(1)}$ Tissue engineering has been applied to many different types of tissues, including cardiac, ${ }^{(2)}$ cartilaginous, ${ }^{(3)}$ corneal,${ }^{(4)}$ bladder, ${ }^{(5)}$ and liver ${ }^{(6)}$ tissues. More recently, stem-cell-like embryonic stem (ES) cells ${ }^{(7)}$ and induced pluripotent stem (iPS) cells ${ }^{(8)}$ have been discovered and incorporated into engineered tissues.

Another important aspect of tissue engineering is the development of suitable scaffold materials. Scaffold materials must control cell adhesion and detachment and exhibit low *Corresponding author: e-mail: akagi008@sekisui.com https://doi.org/10.18494/SAM.2019.2078 
cytotoxicity. Cell adhesion may be due to hydrophilic, hydrophobic, or electrostatic interactions, or arise from interactions via cell adhesion proteins and surface topologies. Cells have been shown to respond to a variety of nanoscale surface topologies mimicking extracellular matrices (ECMs), including nanopits, ${ }^{(9)}$ nanoposts, ${ }^{(10)}$ nanotubes, ${ }^{(11)}$ and nanoislands. ${ }^{(12)}$ Furthermore, other scaffold materials include the following: collagen, ${ }^{(13)}$ laminin, ${ }^{(14)}$ gelatin, ${ }^{(15)}$ poly-1lysine, ${ }^{(16)}$ poly(N-isopropylacrylamide), ${ }^{(17)}$ polylactic acid, ${ }^{(18)}$ polyglycolic acid, ${ }^{(19)}$ calcium carbonate, ${ }^{(20)}$ and hydroxyapatite. ${ }^{(21)}$ Adherent cell types express these proteins on their surface membrane when cultured to allow them to adhere to the surface of a culture dish.

Cells can be detached from the culture dish surface and dissociated from each other by applying trypsin, an enzyme that digests these ECM proteins. This treatment is readily applicable to mouse ES and iPS cells, but trypsin treatment induces apoptosis in human ES cells, resulting in low cell viability after detachment. ${ }^{(22)}$ Another method of cell detachment from a culture dish involves the application of ultraviolet (UV) light. ${ }^{(23)}$ However, this technique of photodegradation irreversibly alters the substrate surface and can damage the cells. ${ }^{(24)}$ Furthermore, temperature-sensitive polymers, such as poly(n-isopropylacrylamide (PIPPAm), have been developed to cause cells to detach when an external stimulus (in this case, heat) is applied. ${ }^{(17)}$ Although adherent cells are easily detached from PIPPAm dishes after PIPPAm becomes hydrophilic at $32{ }^{\circ} \mathrm{C}$ or lower, in the case of medium change at room temperature $\left(25^{\circ} \mathrm{C}\right)$, it is a problem that the cells detach from the dishes at room temperature (under $32{ }^{\circ} \mathrm{C}$ ). Thus, it is necessary to control the temperature so as not to detach the cells using heating systems. Therefore, to eliminate trypsin treatment and the use of special tools and equipment, it is necessary to develop an easy and damage-free cell detachment system.

In the semiconductor field, control over adhesion and detachment is also required for threedimensional packaging and has been achieved by using gas-generating photodecomposable polymers. ${ }^{(25)}$ However these polymers are normally used at high temperatures over $220{ }^{\circ} \mathrm{C}$. In our previous study, we developed a new compound (gas-generating polymer film) that generates $\mathrm{N}_{2}$ gas using only an easy lighting system based on semiconductor processes. Since this technique is simple and can be used at room temperature, we applied it in the field of biotechnology. In particular, we thought that cells in culture could be handled by simple and less damaging methods than the above-mentioned methods by using our gas-generating polymer film. Thus, we developed a novel scaffold using a light-responsive gas-generating resin with the dual functions of cell adhesion and detachment (Fig. 1). In this paper, we report the use and development of a novel cell scaffold that has a nanostructured surface that promotes cell adhesion and also generates gas upon photodecomposition to initiate cell detachment.

\section{Materials and Methods}

\subsection{Fabrication of gas-generation nanoscaffold}

The gas-generation nanoscaffold was composed of a UV-decomposable polymer formed from glycidyl azide polymer (GAP, NOF Corporation, Japan), a photosensitizer (2-isopropylthioxanthone, Tokyo Chemical Industry Co., Ltd., Japan), and a curing agent [poly- 


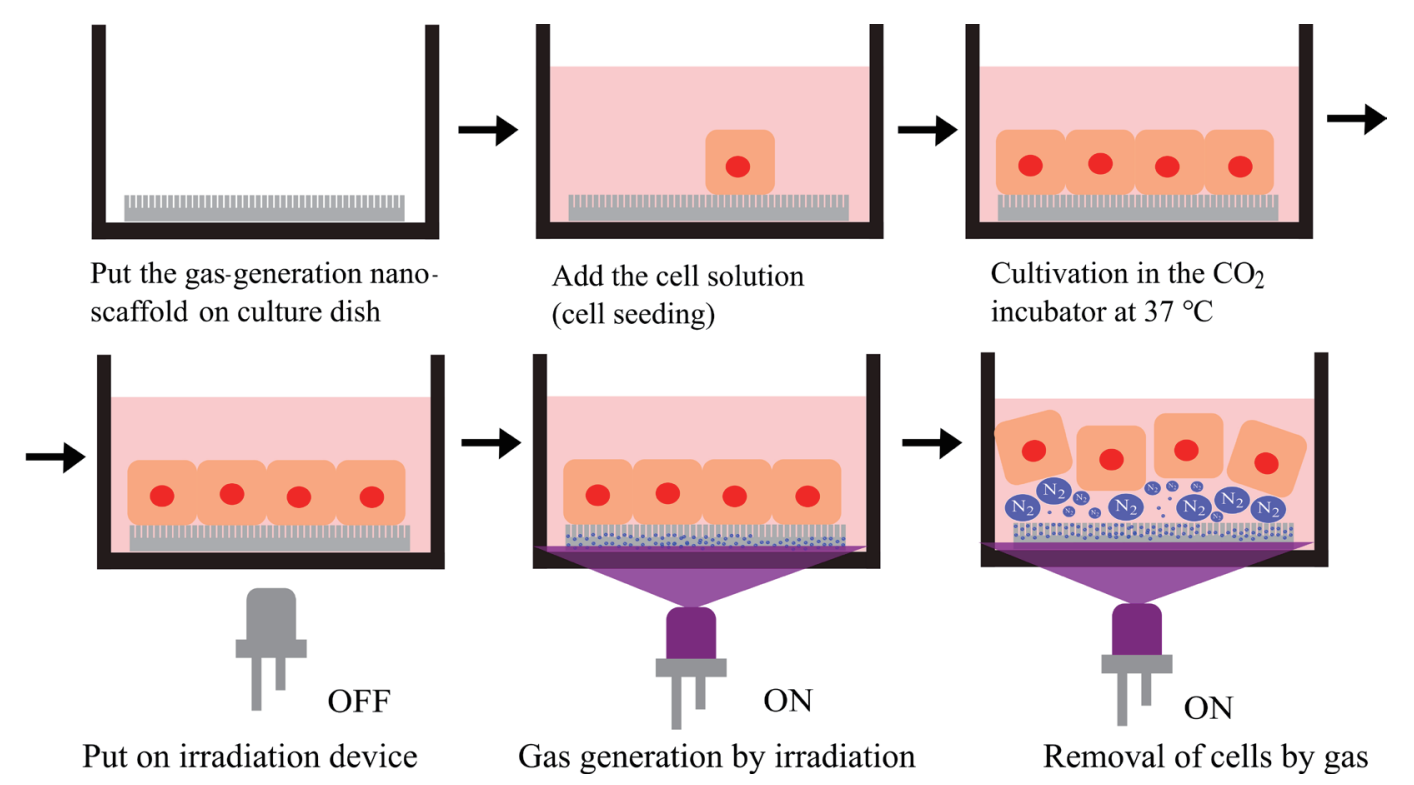

Fig. 1. (Color) Illustration of cell detachment method.

2-(2-ethoxyethoxy)ethyl acrylate, Nippon Shokubai, Japan] in a weight ratio of 100:3:1. These components were thoroughly mixed with a mixer (ARE-310, Thinky Corporation, Japan). The nanostructure was formed by soft lithography, as shown in Fig. 2. A master mold with pillars with a diameter of $230 \mathrm{~nm}$ and a height of $200 \mathrm{~nm}$ was ordered from Scivax Corporation (Japan). The mixture was poured onto a mold, a siliconized polyethylene terephthalate (PET) film (GS-H, Lintec Corporation, Japan) was placed thereon, a load of a $100 \mathrm{~g}$ rubber roller was added, and the mixture was filled into the mold. After $24 \mathrm{~h}$ at $25{ }^{\circ} \mathrm{C}$, the film containing a UV-decomposable polymer was peeled from the mold, and the scaffold was cut to $2 \times 2 \mathrm{~cm}^{2}$. The surface was imaged by scanning electron microscopy (SEM, S-3400N, Hitachi HighTechnologies Corporation, Japan).

\subsection{Evaluation of gas generation}

To measure the amount of gas that was generated from the film, a flow sensor (LG160430, Sensirion Corporation, Switzerland) was attached to a water reservoir with a lightemitting diode (LED) irradiation system via silicone tubing (inner diameter: $3 \mathrm{~mm}$ ). The LED irradiation system comprised a UV-LED (NS395L-5RFS, Nitride Semiconductors Co., Ltd., Japan), an LED driver (AZ-50, Sekisui Chemical Co., Ltd., Japan), and control software (LIMPS ver.1.0, Sekisui Chemical Co., Ltd., Japan). The LED irradiation was controlled by varying the number of pulse signals. The gas-generating film was placed in the reservoir and irradiated for $1 \mathrm{~s}$ with the simultaneous measurement of the amount of gas produced using a flow sensor. The area of $6 \mathrm{~mm}$ in diameter was irradiated with light. 


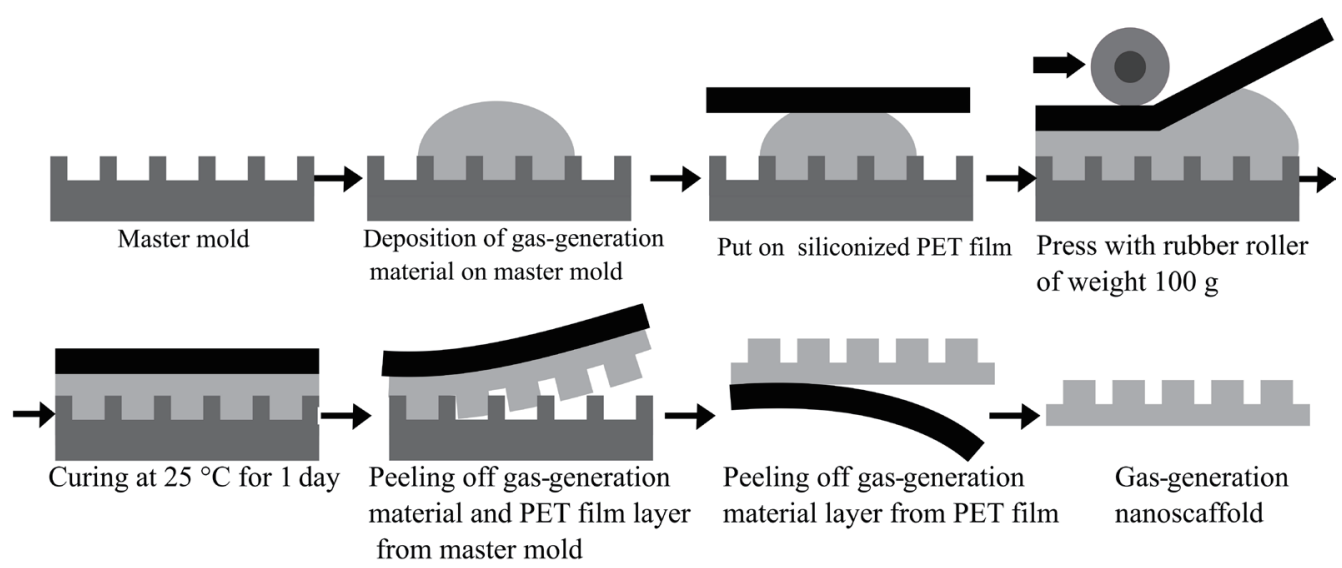

(a)

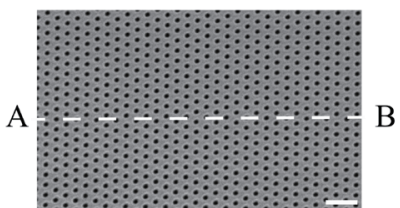

(b)

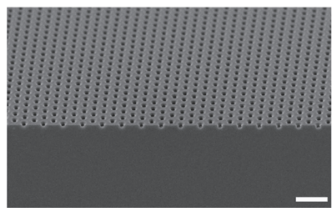

(c)

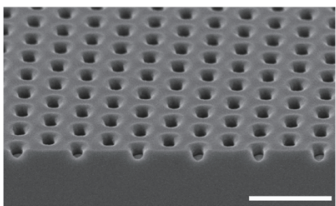

(d)

Fig. 2. Fabrication of gas-generation nanoscaffold. (a) Soft lithography fabrication process. (b) SEM image of the obtained film. (c) SEM image of cross-sectional view along the line A-B, and (d) SEM image of magnification from (c). Scale bar is $1 \mu \mathrm{m}$.

\subsection{Cell culture}

Cells were cultured as described previously. ${ }^{(26)}$ Briefly, human bronchioalveolar carcinoma cells (NCL-H1650), representing adherent cells, were cultured in RPMI 1640 medium (Nakalai Tesque, Japan) containing 10\% fetal bovine serum, $100 \mathrm{U} / \mathrm{mL}$ penicillin-streptomycin (GIBCO, Life Technologies Co., Carlsbad, CA, USA), and $250 \mathrm{ng} / \mathrm{mL}$ Fungizone (GIBCO) on the gasgeneration nanoscaffold in $35 \mathrm{~mm}$ cell culture dishes or a 96-well plate (Corning Inc., USA). The seeding density was $1.0 \times 10^{5}$ cells $/ \mathrm{ml}$ in a $35 \mathrm{~mm}$ dish and $1.0 \times 10^{4}$ cells $/ \mathrm{ml}$ in the 96 well plate. The samples were incubated at $37{ }^{\circ} \mathrm{C}$ in a humidified environment with $5 \% \mathrm{CO}_{2}$ for 3 days. We counted the number of cells present in the photograph of $1360 \times 1024$ pixels taken with a CCD camera (objective lens $\times 20$, CKX41, Olympus Corporation, Japan).

\subsection{Cell viability assay and cytotoxicity assay}

The cells were first cultured on the gas-generation nanoscaffold in a 96-well plate. The viability was measured by quantifying ATP using a CellTiter-GloR Luminescent Cell Viability Assay Kit (Promega, USA). The CellTiter-GloR reagent components were mixed for 2 min on an orbital shaker, added to the wells, and incubated at room temperature for $10 \mathrm{~min}$ to stabilize luminescence signals. The resulting luminescence was then measured using a plate reader (GM3510, Promega, USA). 
Cytotoxicity was measured by DNA-dye intercalation with a dye that can pass only through damaged cell membranes (CellTox ${ }^{\mathrm{TM}}$ Green Cytotoxicity Assay, Promega, USA). The reagent was added to the wells and incubated at room temperature for $15 \mathrm{~min}$ to stabilize the fluorescence signals. The fluorescence was measured using a plate reader at excitation and emission wavelengths of 510 and $530 \mathrm{~nm}$, respectively.

\subsection{Cell detachment: gas-generation nanoscaffold}

After the cells were cultured on the gas-generation nanoscaffold for 3 days, the specimen was irradiated with light to generate gas and detach the cells (Fig. 1). A diameter of $6 \mathrm{~mm}$ was irradiated with an irradiation device. In the irradiation device, the intensity of the LED was controlled by a pulse signal, and irradiation was carried out for $15 \mathrm{~s}$ at level 1 illuminance using control software (LIMPS). The cells were observed under a microscope (CKX41, Olympus Corporation, Japan).

\section{Results and Discussion}

The experimental system consisted of a culture dish, the gas-generation nanoscaffold, and an LED, as shown in Fig. 1. NCL-H1650 cells were cultured on the gas-generation nanoscaffold for 3 days to allow them to attach. After sufficient cell growth, the LED was irradiated from the bottom of the culture dish on which the gas-generation nanoscaffold was placed. $\mathrm{N}_{2}$ gas was generated from this scaffold to detach the cells. The mechanism by which cells are detached from the gas-generation nanoscaffold is thought to be the loss of the adhesive force between the cells and the scaffold owing to the gas generated between the cells and the gas-generation nanoscaffold, causing the cells to detach. In addition, since all the nanoscaffolds are composed of the gas-generating material, it is possible to reliably generate gas in the narrow space between cells and nanoscaffolds, thereby allowing cells to be detached.

The nanostructure was formed by soft lithography, as illustrated in Fig. 2(a). The resulting nanostructures shown in Figs. 2(b)-2(d) were approximately $230 \mathrm{~nm}$ in diameter and $200 \mathrm{~nm}$ in depth. The patterned gas-generation nanoscaffold adhered to the culture dish and remained stable during cell culture. The gas-generation mechanism ${ }^{(27)}$ that drives the cell detachment is represented by Eq. (1). The gas-generation nanoscaffold contains an azido compound, a photosensitizer, and a curing agent, and decomposes upon light irradiation at $395 \mathrm{~nm}$, producing $\mathrm{N}_{2}$ gas.

$$
\left(\mathrm{C}_{3} \mathrm{H}_{5} \mathrm{ON}_{3}\right)_{n}+h v \rightarrow\left(\mathrm{C}_{3} \mathrm{H}_{5} \mathrm{ON}\right)_{n}+n \mathrm{~N}_{2}
$$

Figure 3(a) shows the gas generation over time. $11 \mu \mathrm{l}$ of gas was generated in $90 \mathrm{~s}$ from a 6 -mm-diameter area of this nanoscaffold, and the increase in gas volume was approximately linear, meaning that the gas-generation rate was $0.1 \mu \mathrm{l} / \mathrm{s}$ from $0-90 \mathrm{~s}$. When cells adhere to the scaffold, the distance between the cells and the scaffold is within $1 \mathrm{~mm}$. For example, the volume of cells and nanoscaffold when irradiated with LED light on an area of $6 \mathrm{~mm}$ 


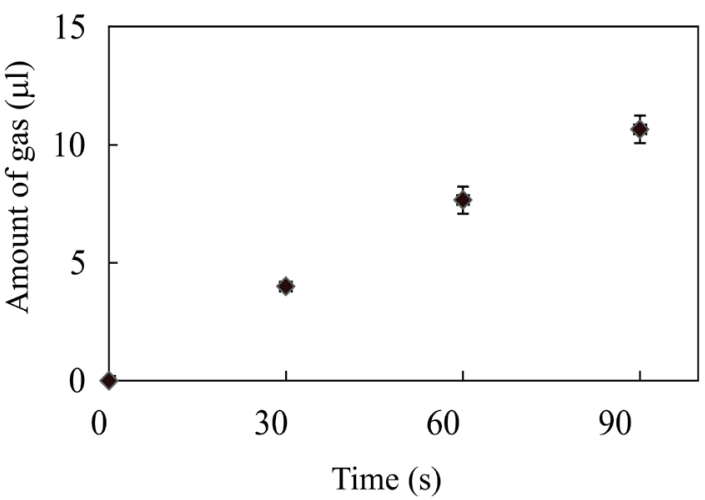

(a)

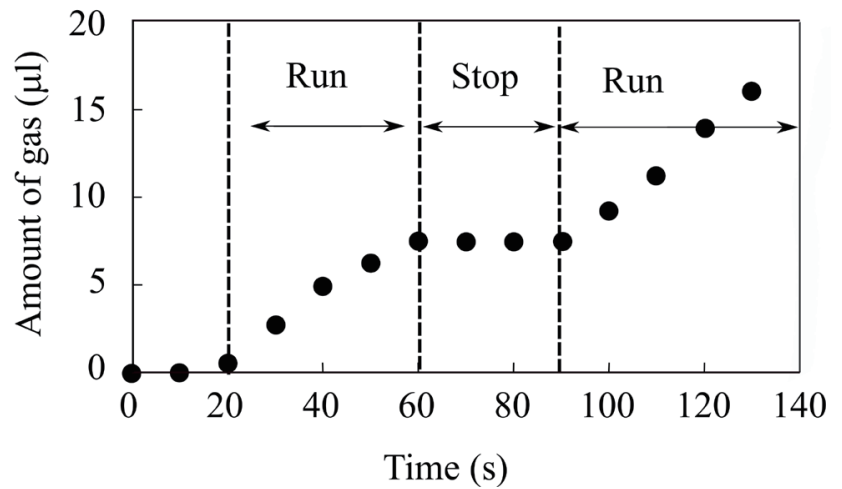

(b)

Fig. 3. Amount of gas generated upon light irradiation. (a) Relationship between gas generation amount and time. (b) Amount of gas generated by second light irradiation after first light irradiation.

diameter was $0.028 \mathrm{~mm}^{3}$. In other words, it is possible to fill the space between the cells and the scaffold with gas in $0.3 \mathrm{~s}$, so that cells can be sufficiently detached by the gas generated from this nanoscaffold. Figure 3(b) shows repeated gas generation. The scaffold material was irradiated with light for $40 \mathrm{~s}$, rested for $30 \mathrm{~s}$, and then irradiated again with light. $7.0 \mu \mathrm{l}$ of gas was emitted with the first light irradiation and $7.5 \mu 1$ of gas was generated in the second. Under these conditions, it was found that the same amount of gas was repeatedly generated at least twice from the nanoscaffold.

Figure 4 shows the cell attachment to the gas-generation nanoscaffold with or without nanostructures over 3 days. $47 \pm 10$ cells $/ \mathrm{mm}^{2}$ were observed on the film without the nanostructure and about twice as many cells, $105 \pm 18$ cells $/ \mathrm{mm}^{2}$, were observed on the gas generation nanoscaffold. This finding shows that the nanoscale holes promote the adhesion

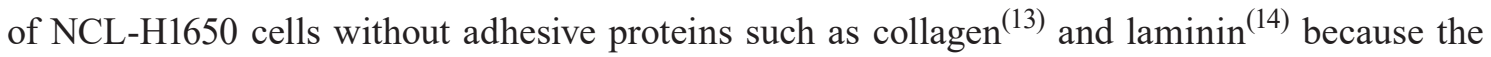
nanoscale topography reproduces the natural extracellular environment. Kaga et al. reported that a nanoscale topography of 500-nm-wide grooves and pillars facilitates the adhesion of Ca922 epithelial cells. ${ }^{(28)}$

The cell viability and cytotoxicity of the gas-generation nanoscaffold were evaluated and the results are shown in Fig. 5. Figure 5(a) shows that the luminescence intensity increased about threefold after over $24 \mathrm{~h}$ of cultivation, confirming that the cells were able to grow on the gasgeneration nanoscaffold. Luminescence intensity indicates the amount of ATP, and the increase in the amount of ATP indicates that the cells are proliferating. A cytotoxic reagent increases fluorescence intensity depending on the amount of DNA. If a cell is dead, the cell membrane breaks and DNA leaks into the culture solution; consequently, fluorescence intensity increases. However, if the cell is alive, since DNA does not leak out from the cell into the culture solution, fluorescence intensity does not increase. The cytotoxicity of the gas-generation nanoscaffold is shown in Fig. 5(b). The fluorescence intensity, which shows cytotoxicity, did not increase after more than $24 \mathrm{~h}$ of cultivation. This result shows that the nanoscaffold is nominally toxic to the cells during cell culture. 


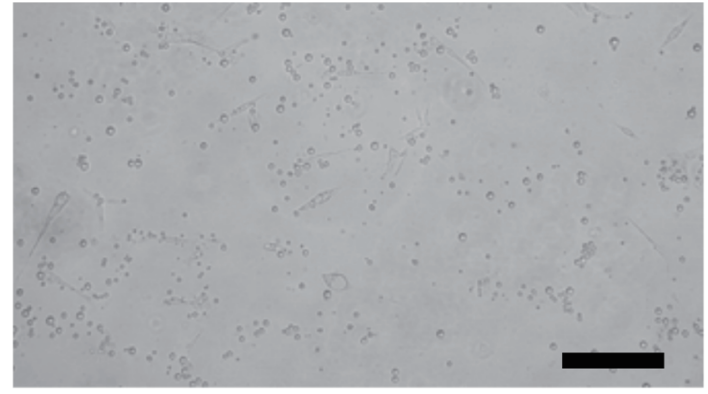

(a)

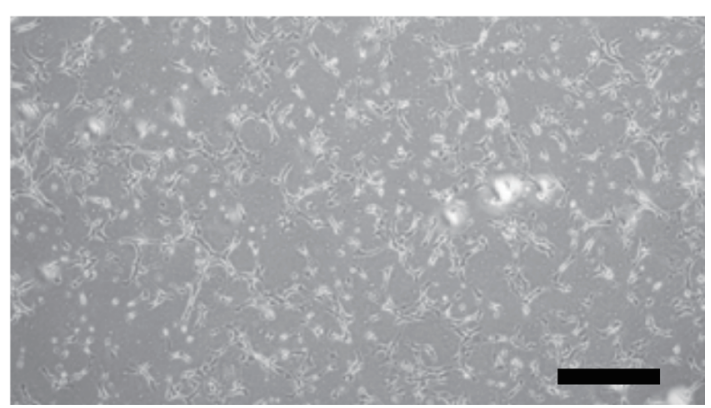

(b)

Fig. 4. Microscopy images showing attachment of NCL-H1650 cells to gas-generation nanoscaffold (a) without nanostructures and (b) with nanostructures. Scale bar is $200 \mu \mathrm{m}$.

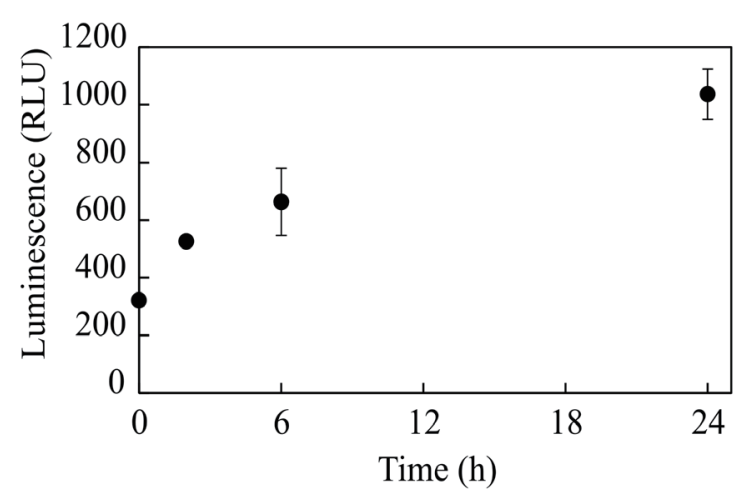

(a)

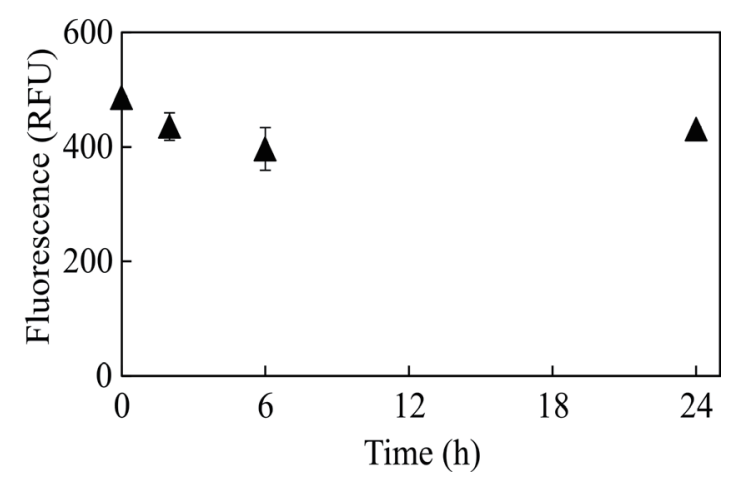

(b)

Fig. 5. Evaluation of cytotoxicity of gas-generation nanoscaffold. (a) Proliferation curve determined by ATP quantification and (b) cytotoxicity curve determined by quantification of dead cells by DNA staining. All data are represented as mean $\pm \mathrm{SD}(n=3)$.

Figure 6 shows the effectiveness of the gas generated upon light irradiation for $15 \mathrm{~s}$ to detach cells from the film. Before the gas generation, the NCL-H1650 cells were attached to the gasgeneration nanoscaffold [Fig. 6(a)], but after gas generation, they were detached [Fig. 6(b)]. In the area within the broken lines (without the gas-generation nanoscaffold) in the photo in Fig. 6, there was $100 \%$ cell detachment after light irradiation. Light was irradiated on an area of $6 \mathrm{~mm}$ diameter, and $3 \times 10^{3}$ cells were recovered. The recovered cells were added to a $35 \mathrm{~mm}$ culture dish and cultured again. After cultivation, approximately $30 \%$ of the cells proliferated. In Fig. 7, the detached cells were again cultured in a $35 \mathrm{~mm}$ culture dish for 6 days. These detached cells could be cultured again. However, because of the small number of cells, it was impossible for them to sufficiently proliferate. This is because the irradiation area of the single LED was narrow and there were few cells that detached from the scaffold material. It seems to be necessary to improve the irradiation device to irradiate a larger area with constant illuminance. By enlarging the irradiation area, many cells can be detached at once, thereby increasing the recovery rate of cells, enabling cells of good condition to be cultured.

It was suggested that our culture system easily enables cell detachment induced by the $\mathrm{N}_{2}$ gas generated without toxicity in a short time. Kikuchi et al. previously reported that cells 


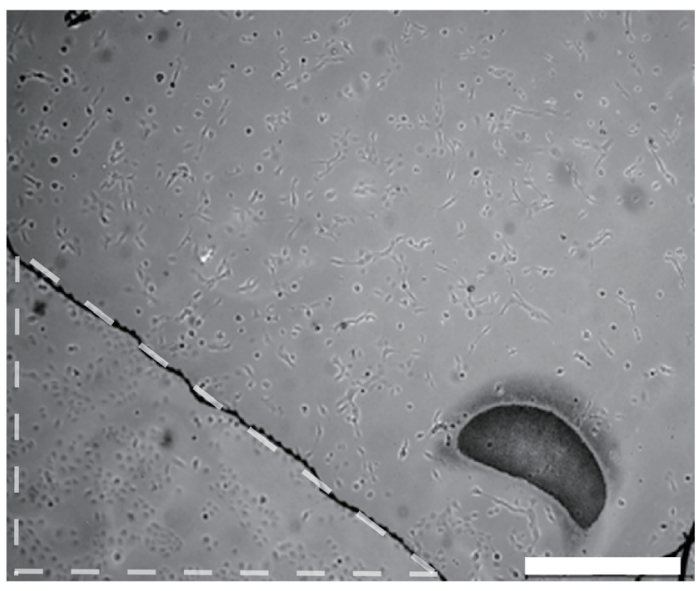

(a)

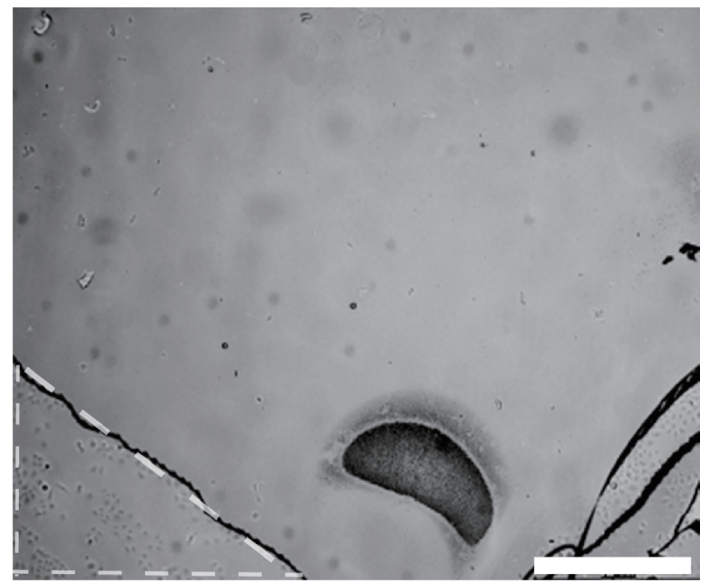

(b)

Fig. 6. Microscopy images showing NCL-H1650 cells detaching as a result of gas generation. The areas with the broken lines are without the gas-generation nanoscaffold. (a) Before light irradiation and (b) after light irradiation. Scale bar is $200 \mu \mathrm{m}$.
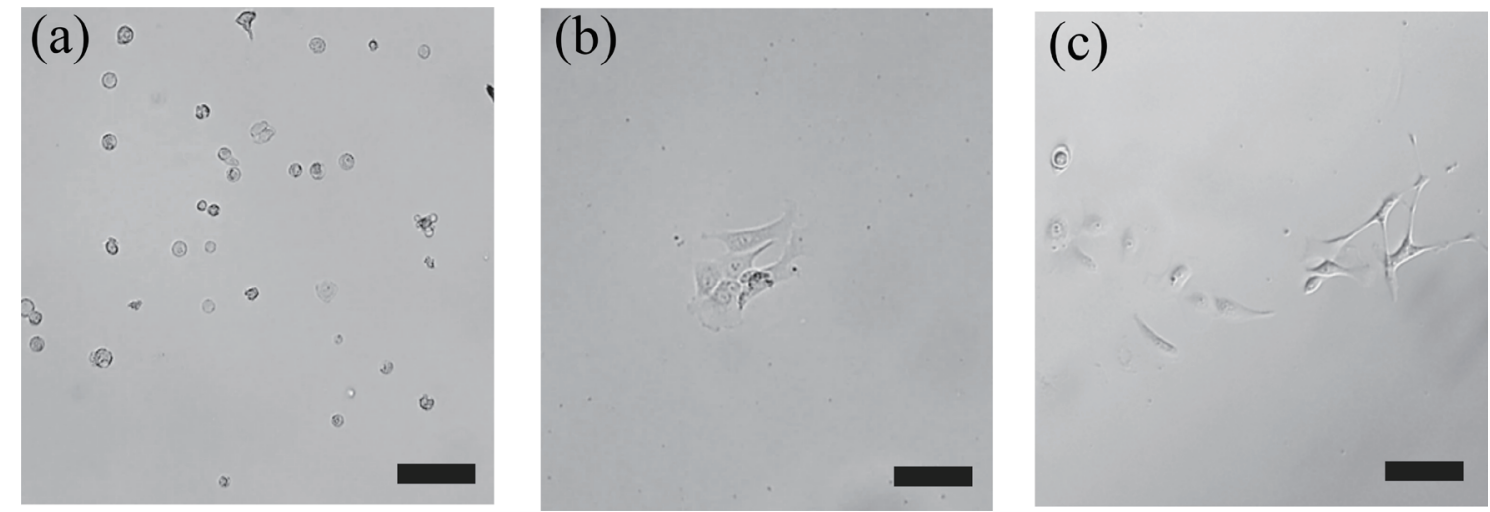

Fig. 7. Microscope images obtained by culturing the cells recovered in Fig. 6(b) from (a) 1 day, (b) 3 days, and (c) 6 days. Scale bar is $50 \mu \mathrm{m}$.

detached from a temperature-responsive polymer [poly(N-isopropylacrylamide, PIPPAm]..$^{(17)}$ This PIPPAm polymer causes cell detachment by becoming hydrophobic below $32{ }^{\circ} \mathrm{C}$. The PIPPAm polymer requires precise temperature control. When the medium in the culture dishes is changed at room temperature outside of an incubator $\left(37^{\circ} \mathrm{C}\right)$, there is a risk of cell detachment unless the temperature is controlled to $32{ }^{\circ} \mathrm{C}$ or higher. On the other hand, the gasgeneration nanoscaffold method proposed here can be carried out easily using an LED system. Since this method does not depend on temperature or a heating system, cells do not detach even if they are taken out of the incubator. Terazono et al. reported that cells detached from the alginate layer by using ethylenediaminetetraacetic acid (EDTA) solution. ${ }^{(29)}$ This method is excellent for peeling a target cell with EDTA, but when recovering cells from the culture dish, a step of removing EDTA is required, which is not simple. Our method is an easy way to detach cells from the scaffold simply by applying light. Furthermore, this method causes minimal 
damage to cells because little heat is generated by the LED and the irradiation time is short. Additionally, by using a small light spot, it is possible to selectively recover cells in a small (single-cell) area on the dishes. Therefore, it is expected to be a new cell culture system with easy and damage-free removal of subcultured cells without the need for the standard trypsin treatment.

\section{Conclusions}

In this report, we have described a novel gas-generation nanoscaffold comprising an azido compound, a photosensitizer, and a curing agent that exhibits photodecomposition-driven gas generation at a rate of $0.1 \mu \mathrm{l} / \mathrm{s}$ for UV light irradiation; $11 \mu \mathrm{l}$ of gas was generated over $90 \mathrm{~s}$ of irradiation. When a nanohole structure was added, twice as many cells adhered to the surface. NCL-H1650 cells adhering to the nanoscaffold could be detached by light irradiation as a result of the gas generation. The proposed gas-generation nanoscaffold method is expected to be useful as a generalized fundamental technique in tissue engineering.

\section{Acknowledgments}

We thank S. Saeki and Y. Muramoto of Nitride Semiconductors Co., Ltd., for providing custom LEDs, K. Otsuka and T. Maki of Promega Corporation for support in the cell assays, K. Yamamoto, Y. Fujii, H. Shimazu, S. Tamaki, and T. Tomaru of Sekisui Chemical Co., Ltd., for discussion and support, and I. Shibata of AIST for assistance of cell culture.

\section{References}

1 R. Langer and J. P. Vacanti: Science 260 (1993) 920.

2 R. Hayashi, M. Yamato, H. Takayanagi, Y. Oie, A. Kubota, Y. Hori, T. Okano, and K. Nishida: Tissue Eng. Part C 16 (2010) 553.

3 R. Shimizu, N. Kamei, N. Adachi, M. Hamanishi, G. Kamei, E. Mahmoud, T. Nakano, T. Iwata, M. Yamato, T. Okano, and M. Ochi: Tissue Eng. Part A 21 (2015).

4 R. Hayashi, M. Yamato, H. Takayanagi, Y. Oie, A. Kubota, Y. Hori, T. Okano, and K. Nishida: Tissue Eng. Part C 16 (2010) 553.

5 E. Watanabe, M. Yamato, Y. Shiroyanagi, K. Tanabe, and T. Okano: Transplantation 91 (2011) 700.

6 Y. Sakai, M. Koike, H. Hasegawa, K. Yamanouchi, A. Soyama, M. Takatsuki, T. Kuroki, K. Ohashi, T. Okano, and S. Eguchi: PLoS One 8 (2013) e70970.

7 J. A. Thomson, J. Itskovitz-Eldor, and S. S. Shapiro: Science 282 (1998) 1145.

8 K. Takahashi and S. Yamanaka: Cell 126 (2006) 663.

9 E. N. Mpoyi, M. Cantini, P. M. Reynolds, N. Gadegaard, M. J. Dalby, and M. Salmerón-Sánchez: ACS Nano $10(2016) 6638$.

10 E. J. Jeong, J. W. Lee, Y. J. Kwark, S. H. Kim, and K. Y. Lee: Colloids Surf., B 123 (2014) 679.

11 Z. Xu, Y. Lai, D. Wu, W. Huang, S. Huang, L. Zhou, and J. Chen: Biomed Res. Int. 2015 (2015) 172898.

12 J. Siegel, M. Polívková, N. S. Kasálková, Z. Kolská, and V. Svorčík: Nanoscale Res. Lett. 17 (2013) 388.

13 S. S. Li, Z. Liu, M. Uzunel, and K. Sundqvist: Blood 108 (2006) 3112.

14 Z. Zhang, P. Zhang, and H. Hu: PLoS One 6 (2011) e19080.

15 F. Bertoni, N. Barbani, P. Giusti, and G. Ciardelli: Biotechnol. Lett. 28 (2006) 697.

16 Y. Akagi, A. Hashigasako, P. Degenaar, S. Iwabuchi, Q. Hasan, Y. Morita, and E. Tamiya: J. Biochem. 134 (2003) 353.

17 A. Kikuchi, M. Okuhara, F. Karikusa, Y. Sakurai, and T. Okano: J. Biomater. Sci., Polym. Ed. 9 (1998) 1331. 
18 K. M. Hossain, M. S. Hasan, D. Boyd, C. D. Rudd, I. Ahmed, and W. Thielemans: Biomacromolecules 15 (2014) 1498.

19 H. Zou, G. Wang, F. Song, and X. Shi: J. Endod. 43 (2017) 745.

20 S. K. Mahmood, M. Zakaria, I. Razak, L. M. Yusof, A. Z. Jaji, I. Tijani, and N. I. Hammadi: Biochem. Biophys. Rep. 23 (2017) 237.

21 A. Anvari-Yazdi, A. Yazdani, T. Talaei-Khozani, and M. Kalantar: Sci. Int. 1 (2013) 1.

22 T. E. Ludwig, M. E. Levenstein, J. M. Jones, W. T. Berggren, E. R. Mitchen, J. L. Frane, L. J. Crandall, C. A. Daigh, K. R Conard, M. S. Piekarczyk, R. A. Llanas, and J. A. Thomson: Nat. Biotechnol. 24 (2006) 185.

23 M. Yamato, C. Konno, M. Utsumi, A. Kikuchi, and T. Okano: Biomaterials 23 (2002) 561.

24 T. A. Kolesnikova, D. Kohler, A. G. Skirtach, and H. Möhwald: ACS Nano. 6 (2012) 9585.

25 T. Tonegawa, T. Asao, S. Nomura, and D. Sugita: Nippon Setchaku Kyoukaishi 8 (2015) 396 (in Japanese).

26 S. Yamamura, E. Yamada, F. Kimura, K. Miyajima, and H. Shigeto: Sensors (Basel) 17 (2017) s17102410.

27 P. W. M. Jacob and A. R. T. Kureishy: Can. J. Chem. 44 (1965) 703.

28 N. Kaga, R. Horiuchi, and A. Yokoyama: e-J. Surf. Sci. Nanotechnol. 15 (2017) 1.

29 H. Terazono, H. Kim, M. Hayashi, A. Hattori, F. Nomura, T. Kaneko, and K. Yasuda: PLoS One 7 (2012) e42485. 